\title{
Clinical Efficacy of Intra-Operative Cell Salvage System in Major Spinal Deformity Surgery
}

Ho Yong Choi, M.D., ${ }^{1}$ Seung-Jae Hyun, M.D., Ph.D., ${ }^{2}$ Ki-Jeong Kim, M.D., Ph.D., ${ }^{2}$ Tae-Ahn Jahng, M.D., Ph.D., ${ }^{2}$ Hyun-Jib Kim, M.D., Ph.D. ${ }^{2}$

Department of Neurosurgery, Kyung Hee University Hospital at Gangdong, Kyung Hee University School of Medicine, Seoul, Korea Department of Neurosurgery, ${ }^{2}$ Spine Center, Seoul National University Bundang Hospital, Seoul National University College of Medicine, Seongnam, Korea

Objective : The purpose of this study was to determine the efficacy of intra-operative cell salvage system (ICS) to decrease the need for allogeneic transfusions in patients undergoing major spinal deformity surgeries.

Methods : A total of 113 consecutive patients undergoing long level posterior spinal segmental instrumented fusion ( $\geq 5$ levels) for spinal deformity correction were enrolled. Data including the osteotomy status, the number of fused segments, estimated blood loss, intra-operative transfusion amount by ICS (Cell Saver ${ }^{\circledR}$, Haemonetics ${ }^{\ominus}$, Baltimore, MA, USA) or allogeneic blood, postoperative transfusion amount, and operative time were collected and analyzed.

Results : The number of patients was 81 in ICS group and 32 in non-ICS group. There were no significant differences in demographic data and comorbidities between the groups. Autotransfusion by ICS system was performed in 53 patients out of 81 in the ICS group (65.4\%) and the amount of transfused blood by ICS was $226.7 \mathrm{~mL}$ in ICS group. The mean intra-operative allogeneic blood transfusion requirement was significantly lower in the ICS group than non-ICS group (2.0 vs. 2.9 units, $p=0.033)$. The regression coefficient of ICS use was -1.036 .

Conclusion : ICS use could decrease the need for intra-operative allogeneic blood transfusion. Specifically, the use of ICS may reduce about one unit amount of allogeneic transfusion in major spinal deformity surgery.

Key Words : Cell salvage system · Allogeneic blood transfusion · Spine surgery.

\section{INTRODUCTION}

Major spinal deformity surgery involving long-level instrumented fusion has the potential for massive blood loss, which necessitates allogeneic blood transfusion ${ }^{20,28)}$. Increased incidence of complications, however, occurs in these patients when allogeneic transfusions are performed. These complications include transmitted diseases such as viral hepatitis, cytomegalovirus infection, and human immunodeficiency virus infection. Furthermore, other potential serious complications include autoimmunization and hypersensitivity reactions ${ }^{11}$.

Accordingly, there are raising concerns about blood conser-

- Received : November 13, 2017 •Revised : February 23, 2018 •Accepted : March 13, 2018

- Address for reprints : Seung-Jae Hyun, M.D., Ph.D.

Department of Neurosurgery, Spine Center, Seoul National University Bundang Hospital, Seoul National University College of Medicine, 82 Gumi-ro 173beon-gil, Bundang-gu, Seongnam 13620, Korea

Tel : +82-31-787-7164, Fax : +82-31-787-4059, E-mail : hyunsj@snu.ac.kr

This is an Open Access article distributed under the terms of the Creative Commons Attribution Non-Commercial License (http://creativecommons.org/licenses/by-nc/4.0) which permits unrestricted non-commercial use, distribution, and reproduction in any medium, provided the original work is properly cited. 
vation strategies to reduce intra-operative allogeneic blood transfusions and associated complications. The techniques of blood conservation include patients positioning to avoid abdominal compression, hypotensive anesthesia, normovolemic hemodilution, application of topical hemostatic agents to decorticated bone, antifibrinolytic therapy, preoperative autologous blood donation, and intra-operative cell salvage system $(\mathrm{ICS})^{3,6,10,19)}$. ICS has been widely used to decrease the need for allogeneic transfusion for organ transplantation surgeries. Recently, ICS has been applied in various spinal surgeries including deformity, tumor, and spondylitis ${ }^{11,14,15,23)}$. There existed, however, conflicting evidence about its efficacy and safety issues $^{9,12,16,17)}$.

The purpose of this study was to evaluate the clinical efficacy and safety of ICS for major spinal deformity surgery. This study also explored factors related to intra-operative allogeneic transfusion volume.

\section{MATERIALS AND METHODS}

A total number of 113 patients undergoing long level $(\geq 5$ levels) posterior spinal fusion surgeries for deformity correction between March 2012 and August 2015 at a single institution were analyzed retrospectively. The patients were not randomized, however, consecutively enrolled. We obtained informed consent from all the patients and also approval from the institutional review board (IRB number B-1603/338-109). Authors decided to set the ICS (Cell Saver ${ }^{\circledR}$, Haemonetics ${ }^{\circ}$, Baltimore, MA, USA) in cases of the intended level of instrumentation was seven or more, or the pedicle subtraction osteotomy was planned (Fig. 1).

Patients who underwent spinal fusion surgeries including five segments or more, regardless of spinal osteotomy, were included. Both revision and primary cases were included. Patients with infectious disease or spinal tumor including metastasis were excluded. Demographic information collected included age, sex, body mass index (BMI), comorbidities, smoking status, preoperative hemoglobin level, primary or revision surgery status, and anti-platelet medication status. Patients taking anti-platelet administration were instructed to hold medication for five days before surgery. Operative details included the osteotomy status, the number of fused segments, estimated blood loss (EBL), intra-operative transfusion amount by ICS or allogeneic blood, postoperative transfusion amount, and surgical time.

To investigate potential complications associated with allogeneic blood transfusion or ICS use, intra-operative and postoperative adverse events were analyzed and compared between groups. Prothrombin time (PT) and activated partial thromboplastic time (aPTT) were checked preoperatively and postoperatively to find out whether ICS related coagulopathy occurred.

All patients underwent a similar operative technique by a single surgeon : standard posterior subperiosteal exposure, facet release, screw insertion by free-hand technique, neural decompression, and transforaminal interbody fusion, and pedicle subtraction osteotomy or posterior vertebral column resection, if needed. After rod assembly, posterior elements or

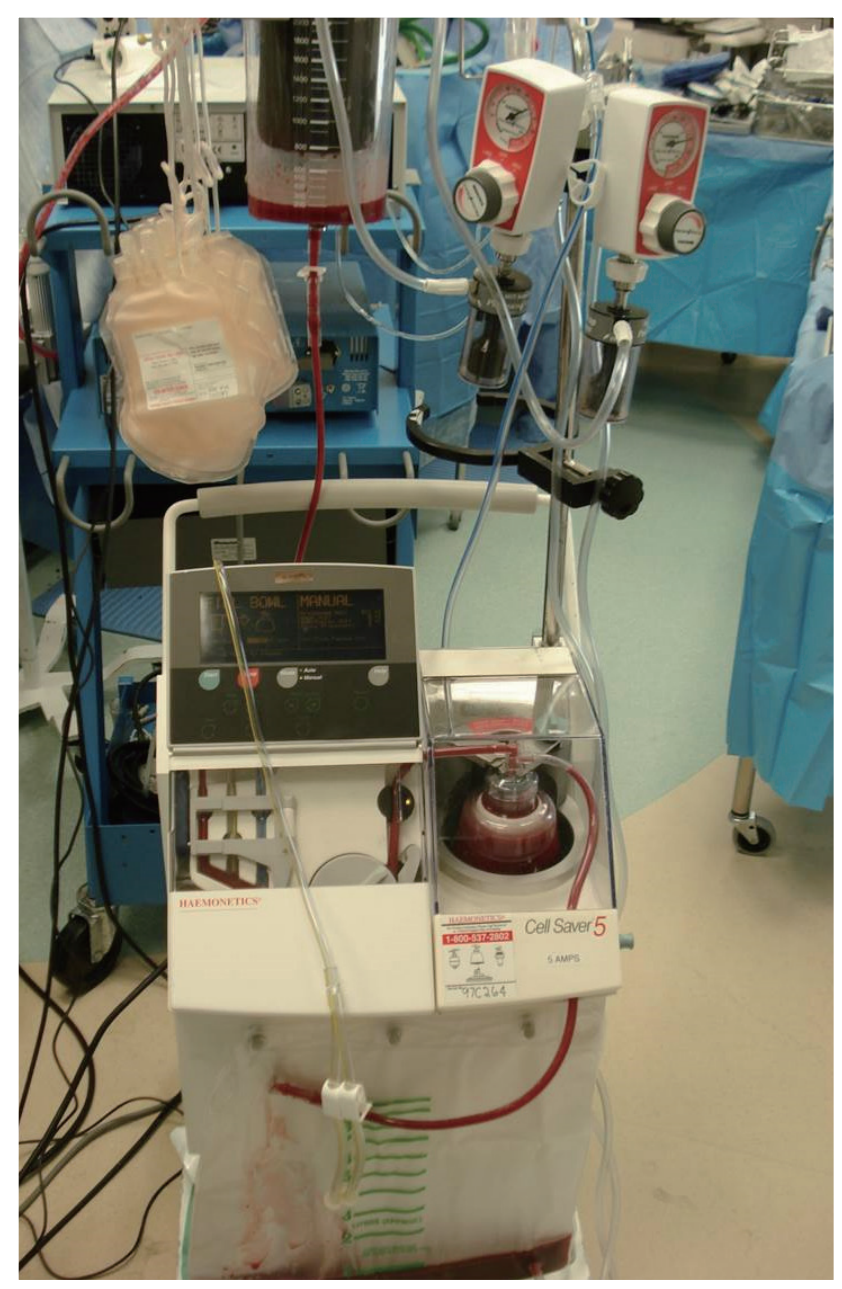

Fig. 1. Photograph showing the intra-operative cell salvage system (Cell Saver $^{\oplus}$, Haemonetics ${ }^{\ominus}$, Baltimore, MA, USA). 
transverse processes were decorticated, followed by posterior onlay fusion or posterolateral fusion in all patients. All wounds were closed with Hemovac ${ }^{\circledR}$ drain, and sometimes adding Jackson-Pratt ${ }^{\circledR}$ drain at suprafascial layer. We used a suction to aspirate shed blood at the level of $300 \mathrm{mmHg}$ (the upper limit recommended by manufacturers) throughout the surgery.

The same blood transfusion guidelines were applied to all patients. Transfusion of allogeneic blood was performed if hemoglobin level decreased to $<7.0 \mathrm{~g} / \mathrm{dL}$ or if anemic symptoms developed, such as decreased systolic blood pressure to $<100$ $\mathrm{mmHg}$, tachycardia $>100$ beats/min, or a oliguria of $<30 \mathrm{~mL} / \mathrm{h}$, following initial fluid infusion with $500 \mathrm{~mL}$ normal saline in patients with a hemoglobin level between 7.0 and $8.0 \mathrm{~g} / \mathrm{dL}^{21,24)}$.

\section{Analysis}

Using SPSS version 22.0 software for Windows (IBM, Corp., Armonk, NY, USA), dichotomous data was compared using chi-square test, and independent t-test was used for comparison of parametric data. A stepwise multiple regression analysis was conducted to investigate the predictive factors of perioperative transfusion volume. Statistical significance was set at $p<0.05$.

\section{RESULTS}

Descriptive analysis was performed to summarize patients and surgical characteristics. Eighty one (71.7\%) patients were operated with the use of ICS, whereas 32 (28.3\%) patients did not use the ICS. Baseline characteristics are summarized in Table 1. Among 113 patients with the median age of 54.1 years, 25 patients (22.1\%) were male and 88 patients (77.9\%) were female. About one third (33.6\%) of patients had a history of undergoing previous spine surgeries. There were no significant differences in demographic data regarding age, sex, BMI, previous surgery status, preoperative hemoglobin level, and comorbidities between the ICS and non-ICS groups. The proportion of patients administrating anti-platelet medication was higher in non-ICS group (16.0 vs. $28.1 \%$ ), however, the difference did not reach statistical significance $(p=0.144)$. There were eight cases of intraoperative complications; dural tear in six patients (one of them underwent revision surgery for prolonged cerebrospinal fluid leakage), screw malposition in one patient who required revision surgery, and chin sore in one patient.

The disease profiles are summarized in Table 2. The most common etiology for surgery was degenerative lumbar flatback syndrome (31 patients), followed by adolescent idiopathic scoliosis (22 patients), post-traumatic kyphosis (17 patients), and postoperative flatback syndrome (11 patients).

Operative characteristics between two groups are presented in Table 3. The proportion of patients who underwent osteotomy was higher in ICS group, but not statistically significant. The number of fused segment was significantly greater in ICS group than that of non-ICS group (9.6 \pm 2.8 vs. $8.3 \pm 2.2, p=0.023)$. The EBL and surgical time between two groups were not different significantly.

The mean amount of autologous blood transfused by ICS was $226.7 \pm 274.9 \mathrm{~mL}$ in ICS group. However, $34.6 \%$ of patients

Table 1. Summary of demographic data

\begin{tabular}{|c|c|c|c|c|}
\hline & All patients $(n=113)$ & ICS group $(n=81)$ & Non-ICS group $(n=32)$ & $p$-value \\
\hline Age (years) & $54.1 \pm 24.5$ & $53.5 \pm 24.7$ & $55.6 \pm 24.2$ & 0.673 \\
\hline Sex, male & $25(22.1)$ & $18(22.2)$ & $7(21.9)$ & 0.968 \\
\hline Body mass index $\left(\mathrm{kg} / \mathrm{m}^{2}\right)$ & $23.5 \pm 4.4$ & $23.8 \pm 4.7$ & $23.0 \pm 3.7$ & 0.383 \\
\hline Hypertension & $45(39.8)$ & $31(38.3)$ & $14(43.8)$ & 0.596 \\
\hline Diabetes & 15 (13.3) & $9(11.1)$ & $6(18.8)$ & 0.335 \\
\hline Smoker & $5(4.4)$ & $2(2.5)$ & $3(9.4)$ & 0.218 \\
\hline Preoperative Hb (g/dL) & $13.0 \pm 1.8$ & $12.9 \pm 1.8$ & $13.2 \pm 1.7$ & 0.218 \\
\hline Previous spine surgery & $38(33.6)$ & $30(37.0)$ & $8(25.0)$ & 0.208 \\
\hline Anti-platelet medication & $22(19.5)$ & $13(16.0)$ & $9(28.1)$ & 0.144 \\
\hline
\end{tabular}

Values are presented as mean \pm standard deviation or number (\%). ICS : intra-operative cell salvage system, $\mathrm{Hb}$ : hemoglobin 
Table 2. Disease profiles

\begin{tabular}{lccc}
\hline & ICS group $(\mathbf{n = 8 1})$ & Non-ICS group $(\mathbf{n}=\mathbf{3 2})$ & All patients $(\mathbf{n}=\mathbf{1 1 3})$ \\
\hline Degenerative flatback syndrome & 20 & 11 & 31 \\
Adolescent idiopathic scoliosis & 15 & 4 & 17 \\
Post-traumatic kyphosis & 13 & 3 & 11 \\
Postoperative flatback syndrome & 8 & 3 & 8 \\
Degenerative lumbar scoliosis & 5 & 3 & 6 \\
Tuberculosis kyphosis & 3 & 0 & 5 \\
Postoperative junctional kyphosis & 5 & 1 & 4 \\
Syndromic scoliosis & 3 & 0 & 3 \\
Scheuermann kyphosis & 3 & 0 & 2 \\
Congenital scoliosis & 2 & 0 & 2 \\
Postlaminectomy kyphosis & 2 & 0 & 1 \\
Ankylosing spondylitis & 1 & 0 & 1 \\
Cervicothoracic kyphosis & 1 & 3 & 2 \\
\hline
\end{tabular}

ICS : intra-operative cell salvage system

Table 3. Operative characteristics

\begin{tabular}{|c|c|c|c|}
\hline & ICS group $(n=81)$ & Non-ICS group $(n=32)$ & $p$-value \\
\hline Osteotomy & $35(43.2)$ & $12(37.5)$ & 0.583 \\
\hline Number of fused segments & $9.6 \pm 2.8$ & $8.3 \pm 2.2$ & 0.023 \\
\hline Estimated blood loss (mL) & $953.7 \pm 774.5$ & $1098.4 \pm 617.5$ & 0.347 \\
\hline Surgical time (minutes) & $393.3 \pm 122.8$ & $358.3 \pm 117.5$ & 0.169 \\
\hline \multicolumn{4}{|l|}{ Intraoperative transfusion amount } \\
\hline By ICS (mL) & $226.7 \pm 274.9$ & - & \\
\hline By allogeneic blood (unit) & $2.0 \pm 1.9$ & $2.9 \pm 2.3$ & 0.033 \\
\hline Postoperative transfusion amount (mL) & $1.0 \pm 1.5$ & $1.2 \pm 1.6$ & 0.948 \\
\hline
\end{tabular}

Values are presented as number (\%). ICS : intraoperative cell salvage system

in ICS group (28/81) were not transfused by ICS in spite of ICS set-up because surgical bleeding was not large enough to be transfused. Focused on patients who were transfused by ICS during surgery, the mean amount of transfused blood by ICS was $346.5 \mathrm{~mL}$.

In patients who used ICS, the mean amount of intra-operative allogeneic transfusion was significantly reduced, compared to the patients in non-ICS group $(2.0 \pm 1.9$ vs. $2.9 \pm 2.3$ units, $p=0.033$ ). The mean amount of postoperative transfusion were similar in both groups $(1.0 \pm 1.5$ vs. $1.2 \pm 1.6$ units, $p=0.948$ ).

\section{Predicting volume of allogeneic blood transfu-} sion

To identify predictive factors of the volume of allogeneic blood transfusion, variables including age, sex, BMI, transfused volume by ICS, surgical time, osteotomy status, number of fused segment, EBL, previous operation, preoperative hemoglobin levels, status of anti-platelet medication, and preoperative coagulation profiles were selected and analyzed by simple regression analysis. Among those variables, surgical time $(p=0.002)$, EBL $(p=0.000)$, osteotomy status $(p=0.040)$, use of ICS ( $p=0.036$ ), and preoperative hemoglobin levels $(p=0.045)$ were statistically significant.

Multiple regression analysis was conducted to adjust various 
Intra-Operative Cell Salvage System I Choi HY, et al.

Table 4. Results of stepwise multiple regression analysis with intraoperative allogeneic transfusion volume as the dependent variable

\begin{tabular}{|c|c|c|c|c|c|}
\hline & Regression coefficient & Standard error & T stat & $p$-value & $95 \% \mathrm{Cl}$ \\
\hline ICS use & -1.036 & 0.291 & -3.555 & 0.001 & -1.614 to -0.458 \\
\hline Preoperative $\mathrm{Hb}$ (g/dL) & -0.308 & 0.073 & -4.231 & 0 & -0.452 to -0.164 \\
\hline Surgical time (minutes) & 0.006 & 0.001 & 3.95 & 0 & 0.003 to 0.008 \\
\hline Estimated blood loss (mL) & 0.001 & 0 & 4.834 & 0 & 0.010 to 0.020 \\
\hline
\end{tabular}

$\mathrm{R}^{2}=0.590$. Cl : confidence interval, ICS : intra-operative cell salvage system, $\mathrm{Hb}$ : hemoglobin

Table 5. Summary of possible transfusion related complications

\begin{tabular}{lccc}
\hline & ICS group $(\mathbf{n = 8 1})$ & Non-ICS group $(\mathbf{n}=\mathbf{3 2})$ & $\mathbf{p}$-value \\
\hline Allergic reaction & $1(1.2)$ & 0 & 0.528 \\
Hemolytic reaction & 0 & $5(15.6)$ & - \\
Electrolyte changes & $14(17.3)$ & 0 & -832 \\
Hemoglobinuria & 0 & 0 & - \\
Hematuria & 0 & 0 & - \\
Acute kidney injury & 0 & & - \\
\hline
\end{tabular}

Values are presented as number (\%). ICS : intra-operative cell salvage system

Table 6. Perioperative coagulation profiles

\begin{tabular}{|c|c|c|c|}
\hline & ICS group $(n=81)$ & Non-ICS group $(n=32)$ & $p$-value \\
\hline PT (INR) & & & 0.457 \\
\hline Baseline & $1.0 \pm 0.1$ & $1.0 \pm 0.1$ & \\
\hline Immediate postoperation & $1.4 \pm 0.3$ & $1.5 \pm 0.4$ & \\
\hline Day 1 postoperation & $1.2 \pm 0.1$ & $1.2 \pm 0.1$ & \\
\hline aPTT (seconds) & & & 0.579 \\
\hline Baseline & $36.5 \pm 4.4$ & $37.2 \pm 4.9$ & \\
\hline Immediate postoperation & $42.2 \pm 21.0$ & $40.5 \pm 10.3$ & \\
\hline Day 1 postoperation & $37.2 \pm 3.7$ & $38.3 \pm 5.1$ & \\
\hline
\end{tabular}

ICS : intraoperative cell salvage system, PT : prothrombin time, INR : international normalized ratio, aPTT : activated partial thromboplastic time

confounding factors, where surgical time and EBL had a significant positive correlation to the volume of intra-operative blood transfusion, whereas, use of ICS and preoperative hemoglobin levels had negative effect (Table 4). The regression coefficient of ICS use was -1.036, which means the use of ICS may reduce allogeneic transfusion.

Regarding transfused volume by ICS as a numerical variable $(\mathrm{mL})$, multiple regression analysis was conducted, however, no significant correlation was found between transfused volume by ICS and that by allogeneic blood.

\section{Transfusion related complications}

A total of 20 possible transfusion related complications occurred in the perioperative period (Table 5). In the ICS group, there were 14 cases (17.3\%) of electrolyte changes and one case of allergic reaction. The control group showed five cases (15.6\%) of electrolyte changes. No significant differences were observed in transfusion related complications between two groups. Now that we did not routinely check urinalysis postoperatively, there was no case of transfusion related hemolytic reaction, hemoglobinuria, hematuria, or acute kidney injury in this study.

To assess the potential ICS related perioperative coagulopa- 
thy, PT and aPTT were checked and analyzed. There were no differences in preoperative and postoperative PT or aPTT between two groups (Table 6). The PT and aPTT commonly reached their highest level at the immediate postoperative period, followed by decrease and stabilization near normal value after postoperative day 1 . There was no case of disseminated coagulopathy during operation in both groups.

\section{DISCUSSION}

ICS has been documented as a valuable method of recycling blood in a safe and effective manner, to avoid such complications related to allogeneic blood transfusion as well as to conserve blood bank resources ${ }^{2,30)}$. In the present study, authors found that ICS use had a significant reducing effect upon the amount of allogeneic blood transfusion during surgery $(2.0 \pm$ 1.9 vs. $2.9 \pm 2.3$ units, $p=0.033$ ). Even if there was disparity about the number of fused segments between two groups, ICS also noted a conservative effect as much as one unit amount of intra-operative allogeneic blood transfusion after multiple regression analysis.

There have been literatures reporting ICS effective in spinal surgeries, consistent with the present study. Lennon et al. ${ }^{16)}$ reported the ICS to be useful in decreasing amount of allogeneic blood transfusion more than $50 \%$ in a group of both pediatric and adult spinal deformity patients. Another investigators suggested that ICS was associated with decreased intra-operative (0.4 vs. $9.1 \mathrm{~mL} / \mathrm{kg})$ and perioperative allogeneic transfusion volume (1.9 vs. $11.1 \mathrm{~mL} / \mathrm{kg})$ in pediatric scoliosis patients $^{4)}$. Recently, Liang and colleagues ${ }^{17)}$ demonstrated in their randomized prospective study that ICS reduced the need for allogeneic blood transfusion in 110 scoliotic patients undergoing posterior spinal fusion.

On the other hand, studies reporting that ICS use was not effective also exist. Kelly and colleagues ${ }^{12)}$ suggested that ICS has limited utility upon cost-effectiveness and reducing transfusion requirements in short-segment lumbar laminectomy and fusion procedures ( $\leq 3$ levels). Previous researchers found that the use of cell saver did not significantly reduce the need for other transfusions in scoliosis surgery ${ }^{31)}$. Furthermore, Gause and colleagues ${ }^{9)}$ insisted that the ICS use did not decrease the need for transfusion, it was even associated with a higher blood loss.
There have been concerns associated with the use of ICS. Complications such as non-immune hemolysis, hematuria, coagulopathy, micro-embolization, contamination with drugs, cleansing solutions and infectious agents, and incomplete washing have been reported ${ }^{8,13)}$. The risks of such complications have decreased with technical advances, staff training, and growing experience with cell salvage ${ }^{1)}$. Previous researcher released a 5-year review of transfusion-related adverse events which reported that the rate of adverse events was substantially less in cell salvage, compared with allogeneic transfusion $(0.027 \% \text { vs. } 0.14 \% \text {, respectively })^{7)}$. Most of recently published literatures also concluded that there were no differences of transfusion related complications in ICS cohort ${ }^{5)}$. In our study, transfusion related complications were not different between groups.

Several investigators reported transfused blood related coagulopathy by ICS. Possible mechanism include the heparinized blood being transfused back to the patients ${ }^{29)}$, washing process discards all platelets and clotting factors ${ }^{26)}$, and activation of coagulation by damaged erythrocytes or mediators released by platelets or leukocytes ${ }^{18)}$. Recent literatures suggested that heparin levels found in transfused blood were zero to insignificant level in modern cell salvage system ${ }^{22,25,27)}$, and patient's coagulation remained normal if the blood loss is $<3.5$ $\mathrm{L}^{26)}$. In the present study, analysis of sequential coagulation profile between two groups showed no significant difference, and disseminated coagulopathy was not evident in operation using ICS.

There are several weak points in this study. This study was conducted in retrospective manner with relatively small sample size. Furthermore, the decision to install the ICS to the patient was determined by the attending surgeon, based on the extent of surgery, and was thus not standardized. These limitations might cause such inconsistent results in which reducing effect of allogeneic blood transfusion by ICS use did not show similar effect when analyzed by transfused volume by ICS. Therefore, further prospective study of larger sample size could confirm the utility of routine use of ICS in major spinal deformity surgery.

\section{CONCLUSION}

The use of ICS could reduce the amount of allogeneic blood 
transfusion in major spinal surgery for deformity correction. Specifically, the use of ICS may reduce about one unit amount of allogeneic transfusion in major spinal deformity surgery.

\section{CONFLICTS OF INTEREST}

No potential conflict of interest relevant to this article was reported.

\section{INFORMED CONSENT}

Informed consent was obtained from all individual participants included in this study.

\section{References}

1. Ashworth A, Klein AA : Cell salvage as part of a blood conservation strategy in anaesthesia. Br J Anaesth 105 : 401-416, 2010

2. Berenholtz SM, Pronovost PJ, Mullany D, Garrett E, Ness PM, Dorman T, et al. : Predictors of transfusion for spinal surgery in Maryland, 1997 to 2000. Transfusion 42 : 183-189, 2002

3. Bess RS, Lenke LG, Bridwell KH, Steger-May K, Hensley M : Wasting of preoperatively donated autologous blood in the surgical treatment of adolescent idiopathic scoliosis. Spine (Phila Pa 1976) 31 : 23752380, 2006

4. Bowen RE, Gardner S, Scaduto AA, Eagan M, Beckstead J : Efficacy of intraoperative cell salvage systems in pediatric idiopathic scoliosis patients undergoing posterior spinal fusion with segmental spinal instrumentation. Spine (Phila Pa 1976) 35 : 246-251, 2010

5. Carless PA, Henry DA, Moxey AJ, O'Connell DL, Brown T, Fergusson DA : Cell salvage for minimising perioperative allogeneic blood transfusion. Cochrane Database Syst Rev (4) : CD001888, 2006

6. Cole JW, Murray DJ, Snider RJ, Bassett GS, Bridwell KH, Lenke LG : Aprotinin reduces blood loss during spinal surgery in children. Spine (Phila Pa 1976) 28 : 2482-2485, 2003

7. Domen RE : Adverse reactions associated with autologous blood transfusion : evaluation and incidence at a large academic hospital. Transfusion 38 : 296-300, 1998

8. Fong J, Gurewitsch ED, Kang HJ, Kump L, Mack PF : An analysis of transfusion practice and the role of intraoperative red blood cell salvage during cesarean delivery. Anesth Analg 104 : 666-672, 2007

9. Gause PR, Siska PA, Westrick ER, Zavatsky J, Irrgang JJ, Kang JD : Efficacy of intraoperative cell saver in decreasing postoperative blood transfusions in instrumented posterior lumbar fusion patients. Spine (Phila Pa 1976) $33:$ :571-575, 2008
10. Gill JB, Chin $Y$, Levin A, Feng $D$ : The use of antifibrinolytic agents in spine surgery. a meta-analysis. J Bone Joint Surg Am 90 : 23992407, 2008

11. Hyun SJ, Lee BH, Park JH, Kim KJ, Jahng TA, Kim HJ : Proximal junctional kyphosis and proximal junctional failure following adult spinal deformity surgery. Korean J Spine 14 : 126-132, 2017

12. Kelly PD, Parker SL, Mendenhall SK, Bible JE, Sivasubramaniam P, Shau $D N$, et al. : Cost-effectiveness of cell saver in short-segment lumbar laminectomy and fusion ( $\leq 3$ levels). Spine (Phila Pa 1976) 40 : E978E985, 2015

13. Keverline JP, Sanders JO : Hematuria associated with low-volume cell saver in pediatric orthopaedics. J Pediatr Orthop 18 : 594-597, 1998

14. Kwon JW, Hyun SJ, Han SH, Kim KJ, Jahng TA : Pyogenic vertebral osteomyelitis: clinical features, diagnosis, and treatment. Korean J Spine $14: 27-34,2017$

15. Lee BH, Hyun SJ, Park JH, Kim KJ : Single stage posterior approach for total resection of presacral giant schwannoma : a technical case report. Korean J Spine 14 : 89-92, 2017

16. Lennon RL, Hosking MP, Gray JR, Klassen RA, Popovsky MA, Warner MA : The effects of intraoperative blood salvage and induced hypotension on transfusion requirements during spinal surgical procedures. Mayo Clin Proc 62 : 1090-1094, 1987

17. Liang J, Shen J, Chua S, Fan Y, Zhai J, Feng B, et al. : Does intraoperative cell salvage system effectively decrease the need for allogeneic transfusions in scoliotic patients undergoing posterior spinal fusion? a prospective randomized study. Eur Spine J 24 : 270-275, 2015

18. Murray DJ, Gress K, Weinstein SL : Coagulopathy after reinfusion of autologous scavenged red blood cells. Anesth Analg 75 : 125-129, 1992

19. Neilipovitz DT : Tranexamic acid for major spinal surgery. Eur Spine J 13 Suppl 1 : S62-S65, 2004

20. Nuttall GA, Horlocker TT, Santrach PJ, Oliver WC Jr, Dekutoski MB, Bryant $S$ : Predictors of blood transfusions in spinal instrumentation and fusion surgery. Spine (Phila Pa 1976) 25 : 596-601, 2000

21. Ovadia D, Luger E, Bickels J, Menachem A, Dekel S : Efficacy of closed wound drainage after total joint arthroplasty. a prospective randomized study. J Arthroplasty 12 : 317-321, 1997

22. Paravicini $D$, Schmitz-Huebner $U$, Stinnesbeck B : Heparin elimination in intraoperative autotransfusion with the haemonetics cell saver. Infusionsther Klin Ernahr 10 : 19-21, 1983

23. Park YS, Hyun SJ, Kim KJ, Jahng TA : Multiple intradural disc herniations masquerading as intradural extramedullary tumors: a case report and review of the literature. Korean J Spine $13:$ 30-32, 2016

24. Parker MJ, Roberts CP, Hay D : Closed suction drainage for hip and knee arthroplasty. A meta-analysis. J Bone Joint Surg Am 86-A : 11461152,2004

25. Serrick CJ, Scholz M, Melo A, Singh O, Noel D : Quality of red blood cells using autotransfusion devices: a comparative analysis. J Extra Corpor Technol 35 : 28-34, 2003

26. Sharp WV, Stark M, Donovan DL : Modern autotransfusion. experience with a washed red cell processing technique. Am J Surg 142 : $522-$ 524,1981 
27. Sistino JJ, Owitz D, Mongero LB : Heparin washout in the pediatric cell saver bowl. J Extra Corpor Technol 24 : 94-96, 1992

28. Urban MK, Beckman J, Gordon M, Urquhart B, Boachie-Adjei 0 : The efficacy of antifibrinolytics in the reduction of blood loss during complex adult reconstructive spine surgery. Spine (Phila Pa 1976) 26 : 11521156, 2001

29. Vorweg M, Muckel G, Knüttgen D, Schindler A, Doehn M : Heparin- induced coagulation disturbance from mechanical autotransfusion. Anaesthesist $47:$ 979-981, 1998

30. Waters JH, Dyga RM, Waters JF, Yazer MH : The volume of returned red blood cells in a large blood salvage program: where does it all go? Transfusion 51 : 2126-2132, 2011

31. Weiss JM, Skaggs D, Tanner J, Tolo V : Cell saver: is it beneficial in scoliosis surgery? J Child Orthop 1 : 221-227, 2007 